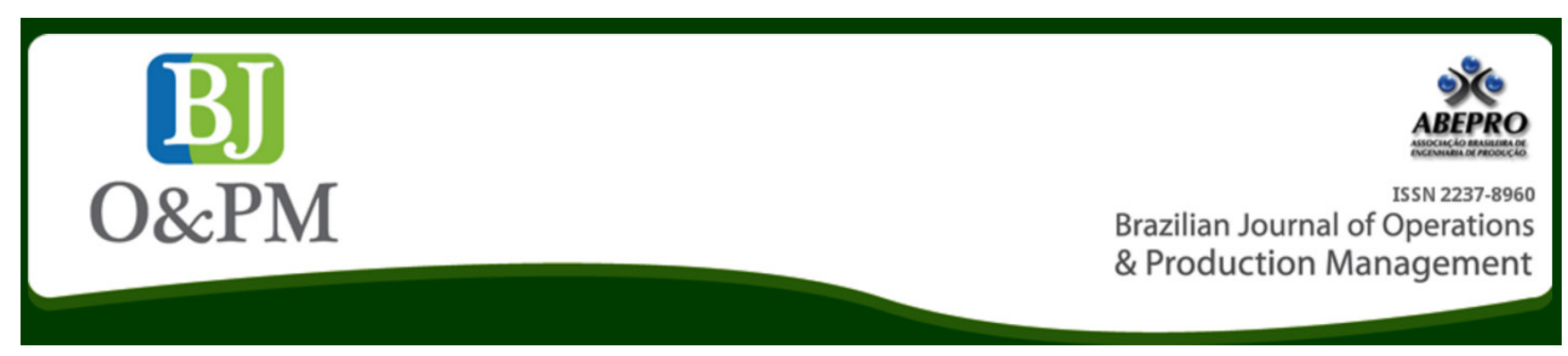

\title{
APPLICATION OF THE TOOLS OF PRODUCTION ENGINEERING FOR THE REDUCTION OF DEAD TIME IN AN ASSEMBLY LINE
}

Mario Fernando Mello ; Gabriel Mino Fassini ${ }^{\mathrm{a}}$

a Lutheran University of Brazil (ULBRA) - Canoas, RS, Brazil

\begin{abstract}
The constant changes in the agricultural equipment market have brought many challenges to the productive sectors inside the organizations. Once the market is increasingly competitive, the industries lack of efficient working methods and companies seek intensely to adapt themselves to a methodology to assist in the standardization of production processes. The main objective of this work is the application of some tools of Production Engineering to improve the operating times in an assembly sector of a metal mechanical industry. The focus is to establish and to define the guidelines of the used methodology, the so-called 'Just in time', to seek the reduction of dead time in the process of the assembly line according to the reality of the companies. Change processes are very conditioned to the environment, the culture of who receives them and leads them. Thus, this project also aims to aid in the maturation of the staff in this cultural aspect, seeking the development of operators in a new operating process.
\end{abstract}

Keywords: Dead times; Methodology; Culture. 
Brazilian Journal of Operations \& Production Management

Volume 14, Número 1, 2017, pp. 2-8 DOI: 10.14488/BJOPM.2017.v14.n1.a1

\section{INTRODUCTION}

Once Brazil is a developing country, agriculture acts as an important development factor. However, it brings with it some concerns in the industrial area where high costs can often derail the industrial development. Along with the advancement of mechanical metal industry, technologies and an increasingly competitive market, it is clear that large companies should not differentiate only on the innovation and performance of their products in the countryside. The productive sector has not been a disorganized environment with low-educated people for a long time and has gained a strong methodological support, making the company increasingly technically equipped and competitive in the market.

When it comes to continuous improvement in machinery and equipment usage, optimization has significance to generate results to industry. However, analyzing the perspective of Production Engineering focused on assembly processes, the emphasis happens because of the importance of improving the physical arrangements in order to achieve cost reduction, standardization of processes, operations and, as a result, an increased productivity.

The major changes experienced by the world economy and especially its oscillations, have reflected and created some difficulties in certain segments of the country. A very affected segment is the market of agricultural machinery. The world is in a current scenario of great opportunities for growth, consolidating many countries as large farming producers.

The company researched is an agricultural implement industry located in the northern region of Rio Grande do Sul state, Brazil. It has a great position in the domestic market and is a sale leader. The company has around 2,200 employees and its constant evolution is a challenge to remain competitive in the market.

Thus, this study aims to demonstrate the application of the concepts of Production Engineering seeking to increase the uptime rate in an assembly line that currently is lacking of a working method. It aims to achieve the development of processes to reduce costs and lead time, in order to increase the company's profitability and serve customers more quickly, thus becoming more competitive in the market.

\section{THEORETICAL FUNDAMENT}

This chapter contains a theoretical framework authors that supported the preparation of this article.

\subsection{Concepts of physical setting}

The physical arrangement, also known as layout, is the way of how the resources used for the manufacture of a product are placed. The layout of the study is not restricted to the positioning of the equipment in the factory plant, it also covers issues such as productive material flow, consumption of components, manufacturing methods, support services and time available for manufacturing.

For Shingo (1996), the production is a process network and operations. In order to achieve improvements in the production process one must distinguish the product flow (process) from the workflow (operation). Therefore, a suitable layout contributes to the improvement of processes and operations

According to Peinaldo et Graemi (2007), there are five basic types of layout:

- Physical Arrangement by Product: In this type of physical arrangement the equipment are arranged in accordance with the assembly sequence of the product.

- Physical Arrangement by Process: Physical arrangement process is characterized by grouping similar equipment in an area. The materials and products are moved when it is necessary another process. This type of physical arrangement does not have the same productivity of the physical arrangement by product, but is flexible and can meet the demand variations.

- Mobile Physical Arrangement: The mobile physical arrangement is a mix of the physical arrangement by process and by product. The materials and products are moved within the cell towards to the next process in a continuous flow.

- Physical Arrangement by Fixed Position: It is the arrangement where the product remains fixed while the resources for its manufacture move up to the product.

- Mixed Physical Arrangement: Mixed physical arrangement is a combination of the previously described physical arrangements.

\subsection{Philosophy Just in Time}

According to Correa et Gianesi (1996), the system 'Just in Time' (JIT) originated in Japan in the mid-1970s, and its basic idea and its development credited to the Toyota Motor Company, which was looking for a management system that could coordinate production with the specific demands of different models and vehicle colors with minimal delay.

For Shingo (1996), however, JIT is more of a technique or a combination of the production management techniques being considered as a complete "philosophy", which includes aspects of the material management, quality management, physical arrangement, product design, work organization and human resource management. The system of 'pulling' 
production from the demand, producing at every stage only the necessary items in necessary quantities and at the required time, became well-known in the West as the Kanban system. This name is given to the card used to authorize the production and moving items along the production process. However, the JIT is much more than a technique or a set of production management techniques, being considered as a complete "Philosophy," which includes aspects of material management, quality management, facility layouts, product design, organization labor and human resources management. Some expressions are often used to translate aspects of the Philosophy 'Just in Time':

- Production without stocks;

- Elimination of waste;

- Streaming manufacturing;

- Continuous effort in solving problems;

- Continuous improvement of processes

To Antunes (2008) although the success of JIT delivery system is trampled in the cultural characteristics of the Japanese people, more and more managers have become convinced that this philosophy is composed of management practices that can be applied anywhere in the world. According to Shingo (1996), JIT system has as its fundamental objective the continuous improvement of the production process. The pursuit of this objective occurs through a mechanism of reduction of stocks. High volume of stocks tend to mask the problems. The objectives of stock reduction, manufacturing reduction, working force involvement, the continuous production flow and improvement, present in JIT philosophy, require some changes in order to get productive resources in a manufacturing company. The traditional layout for companies that produce certain variety of products has been the layout of process or the functional one. In this type of facility layouts, material flows are variable and production routes are diverse, corresponding to the different products produced at the plant. The movement of materials is intense and resources are grouped by function, i.e., similar machines are put together. The fact that the equipment processes several different products that require time for their preparation, impose batch production, generating queues, more stock in process and higher production lead time.

\subsubsection{Just in time objectives in relation to stocks}

The JIT system has the fundamental objective of continuous improvement of the production process. The pursuit of these goals takes place through a mechanism of reduction of stocks, which tend to mask the problems. Inventories have been used to avoid discontinuities of the production process before production problems that can be classified mainly into three major groups.
- Quality problems: When some stages of the production process have quality problems, generating a waste of uncertainly, the stock by placing between these stages and others, it works continuously without suffering from interruptions that occur in earlier stages. Thus, the stock generates independence between the stages of the production process.

- Problems machine break: When a machine for problems of maintenance, the later stages of the process are "fed" by this machine would have to stop if there were not enough stock for the production flow. It continued until the machine was repaired and went into normal production again. In this situation, the stock also generates independence between the stages of the production process.

- Machine preparation of problems: When a machine processes transactions in more than one component or item, you must prepare the machine every change of the processed components. This preparation is cost for the dead period of the equipment, hand labor required in the preparation, the loss of the material at the beginning of the operation, among others. The larger the costs, the greater is the batch to be produced so that these costs are shared by a greater number of parts, reducing, consequently, the cost per unit produced. Large production batches generate stocks, as production runs ahead of demand, being consumed by it in subsequent periods.

It is noticed that the inventory functions as a necessary investment when problems such as those mentioned are present in the production process. The purpose of the JIT philosophy is to reduce inventory, so that problems are visible and can be removed through concentrated and prioritized efforts.

\subsubsection{The benefit of quality}

For Campos (2004), quality is a benefit generated by the JIT system and a pre-requisite for its implementation. Therefore, it constitutes one of the most important elements of the philosophy, next to the search for flexibility. The set of concepts that translate the JIT view of quality management has been called total quality control. This was developed in Japan, based on the works of Joseph M. Juran, Edwards Deming and A. Feigenbaum.

The main concept of total quality control is the assignment of responsibility for quality production. More broadly, this means quality control at source, that is, ensuring that products are made with quality and not just inspecting them after their production. With the assignment of responsibility for the quality of production, start to fit the quality control department the following functions: 
- Training production staff in how to control the quality itself;

- To conduct random quality audits in various sectors of production and providers;

- $\quad$ Provide advice to production employees with regard to problems and quality;

- Supervise final testing of finished products;

- To assist in the dissemination and implementation of quality control concepts by the company. This last task is related to a Japanese innovation current worldwide idea, called quality control circles, a technique that seeks to promote employee participation in identifying and troubleshooting quality.

\subsection{Stages of the layout planning}

For Lobo (2010), time in the layout planning is important because the implementation of a new layout is usually costly. This is why a good planning must be done to avoid relocations or replacements of machines and spaces. In Table 1, the stages of the layout planning are shown.

Table 1. Stages of the layout planning

\begin{tabular}{|c|l|}
\hline \multicolumn{1}{|c}{ Table 1. Stages of the layout planning } \\
\hline $\begin{array}{c}\text { Stage I } \\
\text { Location }\end{array}$ & $\begin{array}{l}\text { It specified the location of the area to which the } \\
\text { layout is planned. This may be an existing area or } \\
\text { a new one. It is important to determine whether } \\
\text { the rearrangement or new layout will be in an area } \\
\text { in use, in a storage area to be disabled, in a new } \\
\text { building or reused elsewhere. }\end{array}$ \\
\hline $\begin{array}{c}\text { General Physical } \\
\text { Arrangement }\end{array}$ & $\begin{array}{l}\text { In this stage, it is specified the relative position } \\
\text { among the various areas. The flow models are } \\
\text { worked and the areas are worked in sets, so the } \\
\text { interrelationships and the general settings of the } \\
\text { areas are established in a crude form. These layout } \\
\text { sketches are called coarse layout, block layout, the } \\
\text { relative location of areas. }\end{array}$ \\
\hline $\begin{array}{c}\text { Stage III } \\
\text { Arrangement }\end{array}$ & $\begin{array}{l}\text { In the detailed physical arrangement, the position of } \\
\text { each machine and equipment is exposed. This stage } \\
\text { specifies each physical characteristic of the area } \\
\text { including the supplies and services. }\end{array}$ \\
\hline $\begin{array}{c}\text { Stage IV } \\
\text { Implementation }\end{array}$ & $\begin{array}{l}\text { In this phase, the movement of machines and } \\
\text { equipment is carried out according to what was } \\
\text { detailed and approved in the stage III, it is also } \\
\text { made a survey of the financial resources necessary } \\
\text { for the implementation. }\end{array}$ \\
\hline
\end{tabular}

Source: Compiled from Lobo (2010)

\section{METHODOLOGY}

As this study aims to suggest improvements in the production process in order to reduce the dead time, it is based on the concepts of Production Engineering. Through a research, the process data were collected for the initial analysis of the critical points. Data were collected and analyzed in the months of April, May and June 2014. The company researched is an industrial company of agricultural equipment located in northern of Rio Grande do Sul state, Brazil, and has approximately 2,200 employees.
It was carried out the evaluation of the current working system of the assembly line of the company above mentioned. The assembly line department has 102 employees operating in approximately $5,000 \mathrm{~m}^{2}$, running the processes of the assembly line in this company. The results are described based on observations in the aspect of the assembly process; in the cultural aspect; in the ergonomic aspect; and in the logistical aspect.

\section{RESULTS}

Initially, it was made an analysis of the current process. The surveys were divided into three distinct main areas. They are:

- Working logic: based on the concepts of ergonomics, short manufacturing, 5S, 'milk run', the technical characteristics of the assembly line as well as the analysis of the current logic of work is raised.

- Functional staff: survey of ergonomic issues, requirements of filling the functions of employees, training, skills and segregation of this information to the profile designed by the company.

- Working environment: survey of environmental safety conditions and auxiliary devices, survey of the layout conditions, survey of the environment among operators.

The analysis of the current situation is made by assessing the applied physical arrangement, composition of flowcharts work on the macro level and study of time and motion of assembly processes.

\subsection{Working logic aspect}

We note the following points about the aspect of working logic, according to the survey data conducted on the current situation:

- Lifting structures as well as assembly and transportation devices are working properly.

- The current logic of supply logistics is deficient in some points making the assembly not possible at the planned time.

- There is no definite supply flow.

- The assembly line does not follow a takt time in an orderly manner, thereby managing the run-in time according to good or bad conducts of the assembly processes.

- $\quad$ The parts with production problems are not assessed before the assembly process and the machine inspection is carried out after the whole assembly of the product. 
The assemblers face some ergonomic problems due to the machine position in the assembly line. The same is assembled from the start to the end of the process at a height of 1.80 meters making the arms of operators get extremely tired at the end of the working day.

Currently, the process of pre-assembly is held in a separate pavilion of the main line with about 2,000 $\mathrm{m}^{2}$ and distant eighty (80) feet. This distance creates a very high logistics costs and consequently vulnerability in a very large system, in the transport, because of the disability of some packages. The parts are damaged affecting the quality of the final product as the assembly line does not evaluate the visual quality of them before the union of the sets.

\subsection{Staff aspect}

It was noticed a serious lack of a working method in the staff, therefore, one of the most difficult obstacles to work is the culture of operational base. It can be seen in this analysis that the operating base cannot follow some basic concepts of an organization. The rules are set aside and turned into exception at work. Nowadays, the company works with 102 employees focused on the assembly process.

\subsection{Working environment aspect}

It was perceived in this analysis that, because the company is not given a modern working method, various problems occur in the workplace hindering a better productivity. They are:

a) Corridors (hall): Blocked by assemblies, clogged by parts packed around awaiting for the assembly process and obstructed by devices and/or tools or objects in general. The lack of space in corridors are caused by obstructions and the disruption of the flow of parts and raw materials. This obstruction of the corridors can also be considered a job security issue, as these objects become obstacles in the traffic of employees.

b) Temperature ranges: Ventilation systems are not efficient resulting in a hot work environment during the summer and the structure does not have a heating system with heating function in the winter.

c) Culture: Organizational culture, which imposes accelerated rhythm of production, and the personal culture of employees still struggling to assimilate, produce at minimum cost with quality and in a clean and organized environment.

\subsection{Description of the intervention}

Depending on the issues, a new conception of physical arrangement was set up, based on the concepts of the concepts of 'Just in Time' that values the production without stocks and manufacturing with continuous flow for assembly operations.

By having these data about the current process, the development focused on reducing the in-process and the optimization of its logistics process and the physical arrangement was started, making the operator work with footage of the suitable working area. The stock that was previously accumulated in 6 machines, now works with only the machine that will be used by the main line, without any floor space for accumulation of unnecessary stock. The pre-assembly line supplies the main line laterally. This new concept has reduced the cost of transportation of pre-assembled components to numbers close to zero. The whole process was based by using an action plane the model $5 \mathrm{~W} 2 \mathrm{H}$ for the transition. To do so, all the leaders of the assembly department, logistics, and the development group responsible for creating the physical arrangement were assembled.

Along with the defined action plan, the physical arrangement started changing. Walking corridors were created, a demarcation located next to the main hall where the assembly operators should move not to interfere in the space that belongs to the flow of the logistics department. This intervention was successful and today all operators only move around in the area allocated to them. In order to eliminate one of the major problems already highlighted in the analysis before the intervention, the main corridors were clear. The logistics and the assembly departments were involved in this stage. So, it was defined a team that initially would be responsible for monitoring and for the cultural development of the operators. It can be concluded that the goal was achieved and today the corridors are free.

In this scenario, it was performed a time measure on April 23rd 2014, analyzing the operative and inoperative times of the production assembly process. After the interventions already described, a new time measure was performed on June 10th 2014 and it was perceived an improvement in the daily performance indicator of operators. Table 2 shows the time measures before and after the improvement actions. It should be noted that Table 2 refers to the production in the assembly process. The percentages do not match and the assembly process show that the operator is performing other tasks that do not correspond to their main functions.

It is clear in Table 2, at the time measure of April 23rd 2014, that analyzing the operative and inoperative times, operators have on average, on a day's work, $50.7 \%$ of their time as dead time, that is, making tasks other than the mounting (assembly). On the other hand, on June 10th 2014, after the improvement actions, we can see an improvement in the indicator that shows the daily performance index of operators. In the survey data before the intervention, 
Brazilian Journal of Operations \& Production Management

Volume 14, Número 1, 2017, pp. 2-8 DOI: 10.14488/BJOPM.2017.v14.n1.a1

Table 2. Functions and percentage data of the measured times

\begin{tabular}{|c|c|c|c|}
\hline FUNCTION & $\begin{array}{c}\text { PERCENTAGE OF } \\
\text { OPERATING TIME 23.04.14 }\end{array}$ & $\begin{array}{c}\text { PERCENTAGE OF } \\
\text { OPERATING TIME 10.06.14 }\end{array}$ & IMPROVEMENT INDEX \\
\hline Assembly & $49.3 \%$ & $62.1 \%$ & $12.8 \%$ \\
\hline Verifying parts & $28.5 \%$ & $10.4 \%$ & \\
\hline Others & $15.2 \%$ & $24.4 \%$ & \\
\hline Tools & $4.3 \%$ & $2,4 \%$ & \\
\hline Maintenance & $1.5 \%$ & 0 & \\
\hline Movement & $1.2 \%$ & $0.7 \%$ & \\
\hline Total & $100 \%$ & $100 \%$ & \\
\hline
\end{tabular}

Source: The authors own.

we note that operators reached less than $50 \%$ of their workday acting in their assigned roles. Comparing the two measurements of time, there is an increase of $12.8 \%$ in the operating time, which means, the operator who spent less than half of his day being productive in his role for the company now reaches numbers above $60 \%$. This is the result of measures taken in relation to production.

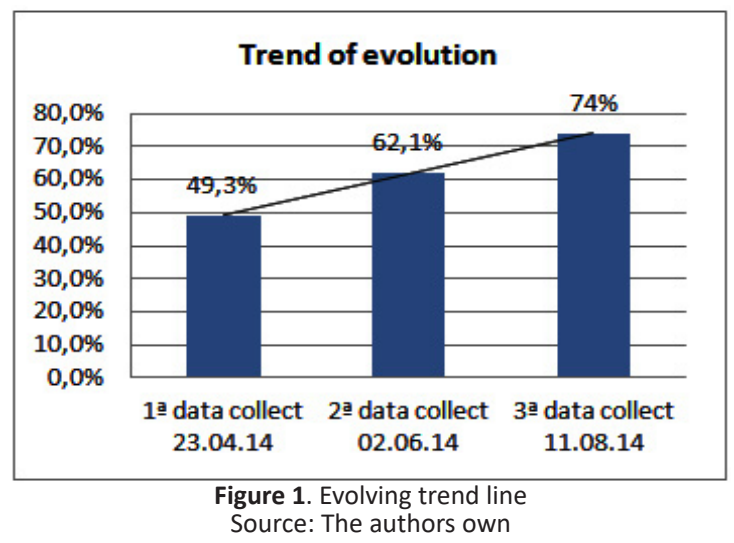

Drawing a trend line as shown in Figure 1 can be achieved in the coming months percentage of $75 \%$ of uptime .

\section{CONCLUSION}

It became clear in this research, the importance of using methodologies of Production Engineering in search of better competitiveness in companies. It is known that the reduction of waste and the improvement of the operational performance enhance the financial performance of organizations. This paper proposed, through the use of production engineering tools, to identify and to improve operative time within an assembly line in an industrial production process. Thus, the overall objective was achieved through the demonstrated results and the analysis of this important issue which is the constant pursuit of continuous improvement.

Regarding the cultural aspect, it was achieved in a short space of time, making the leadership and the operational base understand the new concepts to transform them allies in the change process at work. With the defined action plan, it was initiated the alteration of the physical arrangement with the cleanliness of the entire physical structure of the assembly hall and the demarcation of the tapes of the proposed layout. All employees involved felt valued, reinforcing the importance of the cultural business aspect.

Regarding the working environment aspect, the improvement of the ergonomic aspect comes as a consequence of an entire work performed, as mentioned in the analysis previous to the intervention. The operators used to work for hours standing and with theirs arms raised. Because it is heavy work, operators sometimes ended up extremely tired, reducing their productivity. After the intervention, the operators started working with proper ergonomics positions.

So with the application of Production Engineering tools, it was decided that each department carries out its real function without interfering in the responsibilities of other areas, working with low stock production, product quality and maximum organization in the industry. These features are great allies in reducing dead times, since they help assemblers in the daily process and add much in the cultural development of each worker.

To sum up, because of the importance and relevance of the topic, new incursions of research in this area should be made, increasingly seeking knowledge on the subject and assisting in the search for better productivity and profitability for organizations.

\section{REFERENCES}

Antunes, J. (2008). Sistemas de Produção: conceitos e práticas para projeto e gestão da produção enxuta / Junico Antunes ...[et al.]. - Porto Alegre: Bookman.

Campos, V. F. (2004). TQC - Controle da Qualidade Total (no estilo japonês). Nova Lima - MG: INDG Teconologia e Serviços Ltda.

Casarotto Filho, N. (2011). Elaboração de projetos empresariais: análise estratégica, estudo de viabilidade e plano de negócio. 1. ed. - 3. reimpr. - São Paulo: Atlas. 
Corrêa, H. L., Gianesi, I. G. N. (1996). Just in time, MRP ॥ e OPT: Um enfoque estratégico. 2a Edição. São Paulo: Atlas.

Lobo, R. N. (2010). Gestão da Produção. São Paulo: Erica.

Paladini, E. P. (2011) Gstão da Qualidade: teoria e prática. - 2. ed.- 11. reimpr. - São Paulo: Atlas.

Peinaldo, J. Graeml, A. R. (2007). Administração da Produção: Operações Industriais e Serviços. Curitiba: Unicenp.

Shingo, S. (1996). O Sistema Toyota de Produção do ponto de vista da Engenharia de Produção - 2.ed. - Porto Alegre: Bookman. 